\title{
O condicional de valor evidencial no domínio jornalístico
}

\author{
Fabiana Pirotta Camargo Lourenço \\ Universidade Federal de São Carlos (UFSCar), São Carlos, São Paulo, Brasil \\ fabianapirotta@gmail.com
}

DOI: http://dx.doi.org/10.21165/el.v46i2.1684

\begin{abstract}
Resumo
Este artigo propõe o estudo de um uso evidencial ainda não explorado no português do Brasil (PB), que se dá por meio do condicional (futuro do pretérito), que indicará como o locutor teve acesso à informação transmitida no enunciado - qual a fonte da informação. A partir da teoria funcionalista, objetiva-se fazer uma descrição detalhada do condicional de valor evidencial em contextos reais de uso no PB. Com as ocorrências fornecidas por um corpus composto por gêneros do domínio jornalístico, busca-se descrever seu funcionamento, definindo suas características. Com essa caracterização, será possível verificar se o morfema do condicional pode ser considerado como um marcador gramatical de evidencialidade no PB, assim como ocorre em outras línguas. A descrição possibilitará ainda a verificação da função discursiva desse uso nos gêneros jornalísticos que compõem o corpus.
\end{abstract}

Palavras-chave: evidencialidade; funcionalismo; condicional.

\section{The evidential conditional value in journalistic domain}

\begin{abstract}
This paper proposes the study of a type of evidential marker not yet described in Brazilian Portuguese (BP), the conditional tense, which indicates how the speaker had access to the information conveyed in the statement - what is the source of the information. Based on the functionalist theory, it is intended to make a detailed description of the "conditional evidential value" in real contexts of use in BP. Based on occurrences provided by a corpus formed by genres of the journalistic domain, we aim to describe the functioning of this use, looking to set its characteristics. With this characterization, it will be possible to verify if the conditional morpheme can be considered as a way of grammatically marking evidentiality in BP, a process that happens in other languages. This description will enable, besides, the verification of the discursive function of this use in the journalistic genres that compose the corpus.
\end{abstract}

Keywords: evidentiality; functionalism; conditional.

\section{Introdução}

O significado de uma frase pode ser qualificado de forma a refletir o julgamento do falante sobre a proposição por ele expressa, fenômeno chamado de modalização. Além de poderem ser modalizados, os enunciados também podem explicitar a fonte da informação que transmitem, ou seja, os textos também podem ser avaliados em relação a outra categoria, chamada evidencialidade. Há um uso muito frequente no discurso jornalístico e muito estudado por diversos autores, chamado por Dendale (2010) de "condicional de valor evidencial". Esse uso tem sido considerado como modal, mas também pode ser empregado com valor evidencial - a forma verbal futuro do pretérito indica como o locutor teve acesso à informação transmitida no enunciado/qual a fonte da informação, como se vê nos exemplos abaixo: 
(01) Seriam umas seis horas, mas a noite era evidente. (SQUARTINI, 2001, p. 318)

(02) O animal teria cerca de 60 anos de idade quando morreu e estaria morto entre há 10.000 anos a 15.000 anos, indicou à agência AFP o chefe de expedição, Semion Grigoriev, que qualificou a descoberta de excepcional. (OLIVEIRA, 2013, p. 93)

No exemplo (1), a partir da forma verbal no futuro do pretérito, pode-se concluir que o locutor obteve a informação por raciocínio próprio, ou seja, por inferência, a qual ele chegou por meio de premissas que poderão ser os seus próprios conhecimentos armazenados. Esse tipo de condicional é chamado por Dendale (2010) de condicional de conjectura (conditionnel de conjecture) ou condicional inferencial. Em (2), por outro lado, considera-se que a forma no futuro do pretérito indica que a fonte da informação provém de outrem - o que o locutor faz é repassá-la - esse tipo de condicional é chamado por Dendale (2010) de condicional de retomada da informação (conditionnel de reprise). O que se observa, em ambos os casos, é que o locutor obtém as informações de maneira indireta - em (1), a partir de premissas que não foram diretamente verificadas, e em (2), por intermédio de uma terceira pessoa, tratando-se de um conhecimento cuja validade não foi verificada diretamente pelo locutor.

Apesar de existirem outros autores, além de Dendale (2010), no francês, que tratem desse uso do condicional em outras línguas, tais como no português europeu, e nas línguas românicas em geral (espanhol, italiano e inglês), para o português do Brasil, no entanto, não há descrições que tratem desse emprego. Nesse sentido, esta pesquisa, baseando-se teórica e metodologicamente em pressupostos funcionalistas (NEVES, 2000, DIK, 1980, HENGEVELD; MACKENZIE, 2008, DALL'AGLIO-HATTNHER, 2001), analisando-se a língua em seus usos em contextos reais, tem como um de seus objetivos propor um refinamento da descrição da categoria da evidencialidade no $\mathrm{PB}$, relacionandoa com o condicional. Lança-se a hipótese de que, apesar de a expressão da evidencialidade no PB ser feita primordialmente por meios lexicais, haveria uma forma de marcá-la gramaticalmente, por meio do morfema do futuro do pretérito. Considera-se, então, que, com a marcação do verbo no condicional, se tem uma estrutura que apresenta um estatuto evidencial, sendo o princípio primário regente da evidencialidade, nesses casos, o modo de obtenção da informação, a partir de uma fonte indireta, que poderá ser o próprio falante fazendo suas inferências ou uma fonte diferente dele, cujo relato é repassado adiante.

Fez-se assim uma descrição dos usos do condicional com valor evidencial encontrados em um corpus composto por 300 textos jornalísticos, selecionados igualmente entre editoriais, notícias e artigos de opinião, coletados de edições online do jornal Folha de São Paulo dos anos de 2011 e 2012, analisando-se, ainda, a função discursiva desse condicional dentro do domínio jornalístico.

Essa pesquisa, portanto, se justifica, na medida em que irá fornecer uma descrição de um objeto de pesquisa ainda não explorado no $\mathrm{PB}$, além de contribuir significativamente com aqueles que trabalham com os gêneros jornalísticos, uma vez que o uso do condicional evidencial pelos jornalistas pode ser considerado uma importante estratégia discursiva nesse meio. 


\section{Breves apontamentos sobre a teoria funcionalista}

Como afirma Dall'Aglio-Hattnher (2007), dentro da teoria funcionalista encontrase uma diversidade de pontos de vista e uma gama de diferentes trabalhos, cada um com suas especificidades, que se ocupam em classificar a língua segundo a ótica funcionalista. Dessa forma, apesar de poderem apresentar diferenças em relação a algumas características, a consideração comum de todas as propostas que estão vinculadas à abordagem funcional é a de que a forma é motivada pela função.

Afirmar que a forma é motivada pela função significa dizer que a descrição da língua é feita com base em seu uso efetivo e real, ou seja, ela é observada de acordo com seus usos em determinados contextos. Para Dik (1980), as línguas naturais devem ser consideradas como instrumento de interação social, por meio do qual os falantes interagem no meio social. Dessa forma, a língua nada mais é do que um instrumento de comunicação, caracterizando-se como uma forma de ação que envolve uma interação contínua entre os interlocutores e sociedade, decorrendo daí a sua função primordial, a de fazer comunicar e interagir. É a partir dessa necessidade de comunicação e interação entre os membros de uma comunidade, portanto, que nasce o sistema da língua. É dessa concepção de língua que provém a consideração de que a estrutura gramatical (forma) resulta de fatores extragramaticais (função comunicativa da língua).

Na descrição da língua em uso, a análise dos fenômenos linguísticos, portanto, se dá de forma integrada, ou seja, os níveis sintático e semântico se concretizam no nível pragmático, de modo que a descrição se expande para além dos limites da sentença, uma vez que se descreve olhando para o contexto de uso da língua. Esse é outro ponto comum entre as diversas pesquisas e propostas teóricas fundamentadas na abordagem funcional: a relação entre sintaxe, semântica e discurso. Assim, afirmar que a análise se expande para além dos limites da sentença, significa dizer que ela também leva em conta tanto o falante quanto o ouvinte, ou seja, as necessidades da comunidade linguística.

\section{Os gêneros textuais}

Muitas são as possibilidades teóricas para o estudo dos gêneros textuais. Como afirma Marcuschi (2008, p. 151), o estudo dos gêneros é hoje "uma fértil área interdisciplinar, com atenção especial para a linguagem em funcionamento". O autor aborda as noções de gênero segundo a perspectiva da linguística textual, um dos desdobramentos das escolas de pensamento funcionalista. Dessa forma, o conceito de gênero relaciona-se com as noções de uso e contexto, na medida em que se considera os gêneros textuais como formas de interação estabelecidas e criadas no meio social. Como se sabe, um dos pressupostos básicos do funcionalismo é o de que a língua é um instrumento de comunicação destinado à interação dentro do meio social. Assim, podese ver dentro do conceito de gênero essa função, que lhe é característica.

Como já visto anteriormente, na perspectiva funcionalista, considera-se que a linguagem tem funções que são externas ao sistema linguístico e que essas funções influenciam a organização interna desse sistema. Assim, relaciona-se contexto social e forma linguística, e pode-se notar essa relação dentro de vários registros e gêneros textuais. O texto será então a unidade de sentido e interação, dentro do qual se manifestará o uso da língua, ou seja, as relações que se estabelecem entre falante, ouvinte e 
comunidade linguística, que, por sua vez, determinaram a estrutura linguística, níveis sintáticos e semânticos se concretizando no nível pragmático.

\section{Os gêneros jornalísticos}

No jornalismo, a especificidade dos textos é enorme, de modo que há um estilo ou linguagem denominada "jornalística", que deve estar expressa em todos os gêneros pertencentes a esse domínio. Esse estilo ou linguagem jornalística foi sendo convencionalizado aos poucos. Existem manuais formulados especialmente para instruir os jornalistas sobre a técnica que devem adotar para escrever determinado gênero. Esses manuais denominam-se "manuais de redação jornalística". Seus propósitos (que se mostram, muitas vezes, normativos) são variados: fornecem desde dicas de escrita e normas de padronização para o jornal até instruções para a produção dos textos jornalísticos, como, por exemplo, a exigência da objetividade.

Apesar de serem regidos por certas normas convencionalizadas, cada gênero jornalístico possui suas particularidades, no que diz respeito a sua estruturação. A notícia se configura como o gênero fundamental e básico de cada jornal. Segue uma estrutura bastante convencional e sua função é essencialmente informativa - deve relatar os fatos do evento em foco de forma clara e concisa, sem comentários e interpretação do autor, se configurando como um texto bastante objetivo e imparcial.

Os textos das notícias são curtos e sua estrutura temática geralmente obedece a uma ordem segundo a qual as informações mais importantes devem aparecer primeiro (os tópicos de nível superior ficam em primeiro lugar). Em relação ao tipo textual, as notícias são textos que obedecem a uma estrutura narrativa que pode ser acrescida de exposições e descrições.

No que diz respeito às fontes da informação, é comum que o autor de notícias procure informações extras além das fornecidas sobre o assunto em pauta, para que seu texto se torne mais claro. Assim, quando repassa, em seu texto, declarações de outras pessoas, que possam estar envolvidas de alguma forma com o que está sendo noticiado, essa será mais uma de suas técnicas para garantir a objetividade e imparcialidade do texto, na medida em que estará se isentando da responsabilidade sobre o conteúdo dessas declarações (de outrem).

Os artigos de opinião, por sua vez, são textos em que o autor expõe seu posicionamento ou opinião sobre algum tema que esteja em pauta no jornal. Além de expor seu ponto de vista, o autor tenta sustentá-lo através de diversos tipos de argumentos, tratando-se de um texto argumentativo, que geralmente apresenta os argumentos do mais fraco ao mais forte, a fim de persuadir e convencer o leitor a adotar a opinião expressa. Uma vez que a regra básica estabelecida pelos manuais de redação jornalística é a de objetividade e imparcialidade, nota-se que gêneros opinativos, como os artigos de opinião, ocupam seções pré-determinadas dos jornais, destinadas à veiculação de opinião. O que os diferencia das notícias em relação à fonte da informação é o fato de utilizarem como argumentos declarações de fontes externas que funcionam como âncoras que irão sustentar a opinião assumida pelo autor no decorrer do texto. No entanto, apesar de as ideias defendidas nesse tipo de gênero serem de total responsabilidade do autor, no que diz respeito a essas declarações de outrem, percebe-se uma tendência dos autores em utilizá-las como apoio para o desenvolvimento de sua argumentação, porém, sem comprometer-se com estas. 
Os editoriais, por fim, são textos em que o autor exprime a opinião ou parecer do jornal (como instituição) sobre determinado fato em pauta no dia. Apresentam ideias que mostram o ponto de vista adotado pelo jornal sobre a matéria em destaque, caracterizando-se, portanto, como um gênero opinativo. Configuram-se como textos expositivo-argumentativos, assim como os artigos de opinião. Sua diferença em relação a esse último é o fato de que o jornal, como instituição, goza de maior credibilidade no meio social. Quando utiliza declarações de uma fonte externa em seu texto, o autor o faz para que haja certo embasamento dos argumentos apresentados e defendidos no decorrer do texto.

Como se vê, os gêneros destinados à opinião estão em contraste com as notícias, que são preparadas de acordo com as normas corriqueiras do jornalismo. Nem por isso seus autores estão livres da objetividade, pois, com o intuito de persuadir seu interlocutor, o enunciador-jornalista deve buscar estabelecer um equilíbrio entre 0 (des)comprometimento, que proporcionará certa objetividade à exposição dos fatos, e o comprometimento necessário para poder opinar sobre o assunto com autoridade.

Considera-se como de extrema importância o conhecimento dessas questões, uma vez que elas serão fatores determinantes da ocorrência e do modo como essa ocorrência se dará, nos textos jornalísticos, do objeto de pesquisa em questão: o condicional evidencial.

Introduzidos alguns conceitos relativos aos gêneros textuais que são relevantes para a pesquisa em questão, passa-se agora para uma breve exposição teórica sobre a modalização e evidencialidade, categorias que estão envolvidas na descrição do objeto de pesquisa analisado.

\section{Breves apontamentos teóricos sobre a modalização e a evidencialidade}

A relação entre modalidade e evidencialidade deve ser explicitada, uma vez que, na descrição do condicional evidencial, ao se analisar o valor evidencial que a forma em questão apresenta, outro valor se mostra envolvido: o valor modal epistêmico de incerteza da informação e consequente não comprometimento do locutor com a informação veiculada. Dessa forma, abre-se a possibilidade de o condicional evidencial ser analisado segundo dois domínios, o da modalidade e o da evidencialidade. Faz-se necessário, então, a adoção de um posicionamento a respeito da relação entre esses dois domínios, para que se possa seguir com a descrição do emprego que, de fato, é o objetivo da pesquisa, o uso evidencial do condicional.

Como já explicitado anteriormente, o processo de modalização ocorre quando o significado de uma frase é qualificado de forma a refletir o julgamento do falante sobre a proposição por ela expressa, ou seja, podemos distinguir, na maioria dos enunciados das diversas línguas naturais, um dito, o chamado conteúdo proposicional e uma modalidade, a categoria que expressa o ponto de vista do falante (suas crenças e atitudes) sobre tal conteúdo proposicional.

No português do Brasil, a modalização, segundo Neves (2006), pode ser marcada por meio de expedientes lexicais ou gramaticais: por um verbo, seja ele auxiliar modal (poder, dever) ou de significação plena (indicador de opinião, crença ou saber - crer, achar, considerar, dentre outros); por advérbios (talvez, certamente, realmente); adjetivos (claro, evidente); substantivos (dúvida, certeza) ou até mesmo pelo tempo, aspecto ou modo do verbo da predicação (futuro do pretérito, imperfeito do subjuntivo). 
Os tipos de modalidade mais conhecidos são as modalidades alética, epistêmica e deôntica, sendo as duas últimas as mais básicas e mais estudadas, como salientado por Neves (2006). Por razões de relevância para este trabalho, somente será explicitada a modalidade epistêmica, que se insere no eixo da crença, do conhecimento e do saber, expressando o grau de certeza, evidência ou precisão do falante em relação ao enunciado.

Ao qualificar epistemicamente um enunciado, o falante determina o seu grau de certeza sobre o estado-de-coisas contido na proposição, de modo que na medida em que isso ocorre, ele também acaba por estabelecer seu grau de (des)comprometimento com a verdade da proposição. $\mathrm{O}$ exemplo abaixo ilustra esse tipo de modalidade:

(03) É possível que todos fiquem paralisados caso nenhum seja reativado até o próximo verão local (no meio do ano), mas o governo prevê tomar uma providência ainda neste semestre. (Folha de $S$. Paulo, 10/03/12)

No exemplo (3), o jornalista afirma a possibilidade da ocorrência do estado-decoisas expresso na proposição, com a utilização de um adjetivo modal (possível) - com essa estratégia, não se compromete com o que foi dito, caso o evento expresso na proposição não se realize.

A evidencialidade, assim como a modalização, já foi tratada por diversos autores, a partir de diversas perspectivas em línguas do mundo todo. Para Aikhenvald (2004, p. 1), pode ser definida como "uma categoria gramatical cujo sentido primário é a fonte da informação", ou seja, trata-se da marcação linguística das fontes da informação; a especificação do modo como a informação transmitida no enunciado foi adquirida pelo falante: se ele a testemunhou diretamente, viu ou ouviu; ou se a obteve de maneira indireta, ou seja, se é produto de uma inferência feita por ele mesmo, ou se ele a recebeu de outra pessoa.

Ainda segundo Aikhenvald (2004, p. 1), um quarto das línguas do mundo codifica morfologicamente, ou seja, gramaticalmente, a evidencialidade. No Brasil, no entanto, essa marcação é feita majoritariamente por itens lexicais. Este trabalho, ao sustentar a hipótese de que o condicional seria um marcador evidencial gramatical no PB, considera que existem motivos discursivos que condicionem o aparecimento desse marcador gramatical. Poder-se-ia ainda dizer que esses motivos impõem uma obrigatoriedade de haver essa marcação no contexto jornalístico analisado. Tais motivos discursivos estariam ligados às características do domínio jornalístico vistas anteriormente.

Segundo Dendale e Tasmowski (1994, p. 4), quando o locutor marca em seu enunciado a maneira pela qual obteve a informação transmitida, ele está oferecendo ao seu interlocutor a possibilidade de avaliar por si mesmo a confiabilidade de tal informação. Assim, a indicação do tipo de evidência seria um meio de justificar a validade da informação veiculada, o propósito da marcação das fontes, portanto. Nesse sentido, para Dendale (1991), pode haver a justaposição de dois aspectos: a fonte da informação (aspecto evidencial) e o grau de certeza a respeito da informação (aspecto modal).

Os evidenciais poderão indicar, então, além da fonte da informação do enunciado, o grau de comprometimento do falante com a verdade da proposição, havendo dessa forma uma indecisão a respeito de qual dos valores seria primário. No entanto, a respeito da relação entre modalidade e evidencialidade, o posicionamento adotado por essa pesquisa insere-se na tendência defendida por Dall'Aglio-Hattnher (2001, 2007), Nuyts 
(1993, 1994, 2001), Dendale e Tasmowski (1994, 2001), dentre outros, que considera a evidencialidade como uma categoria hierarquicamente superior à modalidade epistêmica.

Dall'Aglio-Hattnher (2007) considera, apoiada em Nuyts (1993), que todo julgamento modal baseia-se em uma evidência. Assim, o presente trabalho considera que a evidencialidade, além de ser superior à modalidade epistêmica, é determinadora da qualificação epistêmica, ou seja, necessária a ela. A descrição, portanto, considerará como consequências modais os valores modais que surgirem na análise, que serão vistos como provenientes da necessidade de se explicitar as fontes da informação, ou seja, a evidencialidade passa a ser, então, determinadora da qualificação modal.

Nas ocorrências com o condicional evidencial, a forma verbal, no futuro do pretérito, indicará de que maneira o falante teve acesso à informação transmitida no enunciado - qual a fonte dessa informação, como se verá com os procedimentos de análise e descrição, realizados a partir da próxima sessão. Textos pertencentes ao gênero jornalístico são um ambiente fértil para o aparecimento desse uso evidencial do condicional, bastante estudado na língua francesa por Dendale (2010), que o nomeou de "condicional de valor evidencial".

\section{O condicional evidencial}

O chamado condicional de valor evidencial configura-se na ocorrência da forma verbal conhecida como futuro do pretérito, que, inserida no enunciado, indica que o locutor teve acesso à informação que veicula por meios indiretos. Isso significa dizer que ele obteve essa informação por "empréstimo" de uma fonte externa, configurando uma situação de reportatividade (evidencialidade reportativa), no qual o locutor repassa conhecimentos de outrem adiante. Por outro lado, a informação veiculada pelo locutor pode também ser resultado de uma inferência pessoal, ou seja, são casos em que a informação provém do próprio locutor, que a obteve por raciocínio próprio a partir de seus conhecimentos prévios (evidencialidade inferencial).

Ao ser inserido nos enunciados, o condicional poderá trazer consigo traços que lhe são intrínsecos. Dentre esses traços, como citado acima, está o caráter de incerteza ou não confirmação da informação posta no condicional, que passa a figurar como hipótese ou suposição. Coexiste, com esse traço modal, o evidencial, ou seja, a possibilidade de a forma verbal indicar que a fonte da informação foi obtida por meios indiretos. Para este trabalho, uma vez que se considera a evidencialidade como uma categoria distinta e superior à modalidade, o valor evidencial do condicional será visto como primário, sendo seus valores modais secundários, vistos como consequências da explicitação da fonte da informação, o que significa que as informações veiculadas, na maioria dos casos, adquirem um caráter de incerteza e não confirmação, justamente pelo fato de o locutor tê-las obtido por meios indiretos.

Antes de passar à análise dos dados, é necessário ressaltar que o condicional, como se viu acima, poderá veicular dois tipos de evidencialidade, a reportativa e a inferencial. A nomeação dos dois tipos de condicional evidencial, portanto, seguiu a terminologia empregada por Dendale (2010), no francês. Esse autor adota, para o condicional que veicula informação reportativa, o termo condicional de retomada da informação, e para 
o condicional que veicula informação inferencial, o termo condicional de conjectura ou inferencial.

\section{O condicional evidencial no PB: um marcador gramatical?}

Para se tentar comprovar a hipótese de que o morfema verbal do condicional é capaz de veicular sentido evidencial, constituindo-se em um meio gramatical de marcar evidencialidade indireta, foram feitos testes de substituição. Com esses testes, pode-se visualizar o uso evidencial do condicional, na medida em que a substituição desse tempo por outros tempos verbais do modo indicativo impossibilita o sentido evidencial em questão. Dessa forma, foi possível também verificar se outros tempos verbais do PB podem marcar evidencialidade, como se verá abaixo.

(04) Na ocasião, segundo a Folha apurou, Kassab teria autorizado o petista a escolher o nome que quisesse dentro da legenda. (Folha de S. Paulo, 09/01/12, grifo nosso)

(04a) Na ocasião, segundo a Folha apurou, Kassab autorizou o petista a escolher o nome que quisesse dentro da legenda.

(04b) Na ocasião, segundo a Folha apurou, Kassab tinha autorizado/autorizara o petista a escolher o nome que quisesse dentro da legenda.

No exemplo acima, comprova-se que somente na versão original do enunciado, em (04), pode-se denominar o tempo verbal em uso, de condicional de retomada da informação, ou seja, somente nesse caso pode-se dizer que o condicional veicula um sentido evidencial reportativo. Assim, em (04), o jornalista, usando o condicional, reforça a obtenção indireta da informação que repassa, indicando que a obteve de uma fonte externa. Dada a estranheza relacionada ao caráter externo da fonte, portanto, a informação adquire um caráter de não confirmação - o jornalista quer ressaltar que não verificou diretamente a validade da informação veiculada, terminando, assim, por não se comprometer com esta, estabelecendo uma distância em relação ao que diz.

Em (04a), o pretérito perfeito do indicativo exclui a leitura evidencial do verbo, uma vez que, com tal morfema, a informação veiculada se mostra como certa, pois o tempo verbal em questão veicula ações que ocorreram no passado e já terminaram, ou seja, indica fatos conclusos e pontuais. Assim, pode-se dizer que o valor temporal em questão exclui qualquer possibilidade de que haja veiculação de sentidos evidenciais por esse tempo verbal. Usando o pretérito perfeito, o locutor, de imediato, já estaria confirmando a informação que obteve com a Folha, e, nesse sentido, não estaria se preocupando em manter uma distância em relação ao que diz.

Em (04b), o mesmo ocorre - a forma composta do pretérito mais que perfeito indica, primariamente, um sentido temporal, uma ação que já ocorreu no passado, havendo, portanto, uma certeza maior da informação que é transmitida por esse tempo verbal. O jornalista, então, evita utilizar também essa forma, uma vez que, com ela, faz parecer que confia plenamente na Folha, havendo, dessa forma, o estabelecimento de comprometimento em relação ao que está sendo dito.

Outros testes foram feitos, também se substituindo o condicional em (05) pelas formas do futuro do presente - a forma perifrástica, na versão $a$, e a forma sintética, na versão $b$ : 
(05) Em troca, o prefeito selaria o compromisso de apoiar a reeleição de Alckmin em 2014. (Folha de S. Paulo, 09/01/12, grifo nosso)

(05a) Em troca, o prefeito vai selar o compromisso de apoiar a reeleição de Alckmin em 2014.

(05b) Em troca, o prefeito selará o compromisso de apoiar a reeleição de Alckmin em 2014.

O que se observa, com essas substituições, é que o sentido evidencial reportativo e suas características também inexistem em (05a) e (05b), não sendo veiculado pelos verbos que aparecem nessas versões, uma vez que o futuro do presente sugere uma maior factualidade/certeza dos fatos veiculados. O jornalista obtém a informação que veicula em (05) com uma fonte externa, citada anteriormente no corpo do texto (o prefeito Kassab). Assim, em (05), com o condicional, o locutor pretende reforçar o caráter externo e indireto da informação, estabelecendo, com isso, mais uma vez, um distanciamento em relação a esta, que adquire um caráter de incerteza e não confirmação, proveniente justamente da forma indireta de obtenção da mesma - com essa estratégia, o jornalista deixa claro seu não comprometimento com o que está expondo. Por sua vez, se utilizasse as formas do futuro do presente, como em (05a) e (05b), esse distanciamento estaria comprometido, uma vez que a maior factualidade sugerida por esse tempo predomina.

Em relação aos sentidos evidenciais inferenciais, os mesmos testes foram feitos para se confirmar a possibilidade de veiculação desse sentido por outros tempos verbais que não o condicional, como se pode perceber no exemplo abaixo:

(06) Lula diria sobre a crise exatamente o que Dilma disse ontem: não é pela via de ajustes fiscais recessivos que se resolve o problema. Mas Lula subiria num banquinho hipotético para gritar o seu ponto, recheando-o, preferencialmente, com histórias de seu tempo de negociador sindical. (Folha de S. Paulo, 04/10/11, grifo nosso)

(06a) Lula disse sobre a crise exatamente o que Dilma disse ontem... Mas Lula subiu num banquinho $[\ldots]$.

(06b) Lula tinha dito/dissera sobre a crise exatamente o que Dilma disse ontem... Mas Lula tinha subido/subira num banquinho $[\ldots]$.

(06c) Lula diz sobre a crise exatamente o que Dilma disse ontem... Mas Lula sobe num banquinho [...].

O exemplo (06a) está no pretérito perfeito, (06b), no pretérito mais que perfeito, e (06c), no presente. Nesses casos, sobressai o sentido temporal dos referidos tempos verbais, não sendo possível, portanto, que se veicule o sentido evidencial inferencial, assim como veiculado pelo condicional de conjectura, na versão original do enunciado. Ao utilizar o condicional, o locutor, a partir de premissas, compostas por seu conhecimento a respeito do comportamento de Lula, conhecimento adquirido durante sua vivência em sociedade, e amplamente difundido por fontes externas de meios de comunicação diversos, infere que Lula diria sobre a crise exatamente o mesmo que Dilma, mas subiria em um banquinho "hipotético".

Apesar de a origem da informação ser o próprio locutor, este a infere a partir de evidências indiretas, pois o conhecimento que ele possui a respeito do comportamento de Lula, utilizado como premissa para chegar às informações, pode ser questionado e não se constitui como verdade absoluta. Assim, a informação adquire um caráter hipotético, ausente em (06) $a, b$ e $c$, pois o valor temporal dos tempos verbais em questão indicam 
que os fatos veiculados já ocorreram, caracterizando-se como efetivos e pontuais (em (06a) e (06b)) ou estão ocorrendo no momento da fala (em (06c)).

Concluindo, foi possível observar, com os testes realizados, que o condicional pode ser considerado uma forma especializada de se marcar gramaticalmente a evidencialidade indireta (reportativa e inferencial) no PB. Essa tendência de se considerar a evidencialidade como um fenômeno gramatical interno ao sistema verbal, ligada às formas do condicional, não é recente, tendo sido observada para a maioria das línguas românicas, como indica, por exemplo, Squartini (2001) em seu trabalho. Passa-se agora para a descrição e caracterização dos dois tipos de condicional evidencial analisados.

\section{O condicional evidencial de retomada da informação}

Em relação ao condicional de retomada da informação verificou-se, inicialmente, que ocorre apenas em frases declarativas, nas quais, tipicamente, o locutor constata algum fato. Nessas frases, ainda, a fonte da informação contida no enunciado estará sempre referida, se não no próprio enunciado em que o condicional aparece, em algum momento anterior do co-texto.

Nos enunciados em que esse tipo de condicional evidencial ocorre, é comum também o aparecimento de outros marcadores de informação relatada. O jornalista recorre a fórmulas introdutórias de discurso relatado, dentre as quais, "segundo $X$ " e "de acordo com X". Além desse recurso, notou-se que ao atribuir a informação a outras fontes enunciativas, o jornalista tende a utilizar uma grande diversidade de verbos declarativos ('dizer', 'afirmar', 'argumentar', 'informar', dentre outros).

É notório, portanto, o esforço do jornalista em indicar que se trata de informações obtidas indiretamente - a todo tempo ele reforça que não são informações verificadas por ele, mas sim, obtidas com fontes externas. O condicional, portanto, assume, juntamente com os outros marcadores de evidencialidade reportativa, a função de ressaltar a obtenção indireta da informação pelo locutor e, dessa forma, garantir sua desresponsabilização em relação aos conteúdos veiculados. É o que se verá abaixo, com o exemplo.

(07) O "Figaro" informa ainda que também o Hezbollah fez contatos com a oposição síria, que, sempre de acordo com o matutino francês, estaria disposta, uma vez no poder, a reequilibrar as relações com Teerã, hoje de intimidade absoluta, mas sem adotar posições anti-iranianas. (Folha de $S$. Paulo, 01/09/11)

Em (07), a característica que se verifica inicialmente é a indicação de que a informação foi obtida através de terceiros, não sendo uma informação verificada diretamente pelo próprio locutor. O jornalista reforça de várias formas que a informação foi obtida de maneira indireta: identifica a fonte externa - o "Fígaro", o "matutino francês"; utiliza verbos declarativos - "O 'Figaro' informa que [...]”; outros marcadores de informação reportativa juntamente com o advérbio "sempre" para enfatizar que a informação provém unicamente do "Fígaro" - "sempre de acordo com o matutino francês"; e por fim, o condicional, ressaltando e reafirmando que os fatos foram validados por outra instância além do locutor.

Dessa forma, o condicional de retomada da informação, juntamente com outros marcadores expressos anteriormente no enunciado, assume o papel de indicar que a informação foi retomada pelo locutor, ou seja, ao utilizar essa forma, o locutor procura 
mostrar que a informação não vem de sua comprovação direta, mas foi validada por outra pessoa e, portanto, obtida de modo indireto.

A obtenção indireta dos fatos, com consequente atribuição da informação a uma fonte externa, traz estranheza a essa informação, que leva a sua caracterização como incerta e não confirmada. Trata-se de uma informação em relação à qual o locutor não pode se comprometer, por não ter tido a oportunidade de confirmá-la diretamente. Assim, com o condicional de retomada da informação, o jornalista estabelece um distanciamento em relação à informação obtida com terceiros, havendo um não comprometimento do locutor em relação a esta. Como se viu anteriormente, os jornalistas estão sujeitos a códigos de ética estabelecidos pelo jornal, que prezam por esse distanciamento, uma vez que se deve ter extrema cautela em relação à veiculação de conhecimentos obtidos de forma indireta, principalmente em relação àqueles obtidos a partir de outras fontes.

As características atribuídas ao condicional de retomada da informação foram então, as seguintes:

a) ocorre em frases declarativas em que a fonte da informação está sempre referida no enunciado ou em algum momento do contexto textual;

b) ocorre em frases em que frequentemente também se situam outros marcadores de informação reportativa;

c) reforça a obtenção indireta da informação, ou seja, que o locutor a obteve a partir de uma fonte externa, e que a comprovação de tal informação está fora de seu alcance;

d) indica que a informação é incerta e não confirmada pelo locutor;

e) indica que o locutor não quer e não pode se comprometer com a informação, havendo então o estabelecimento de um distanciamento em relação a esta.

\section{O condicional evidencial de conjectura ou inferencial}

O condicional de conjectura ou inferencial é usado pelo locutor quando este quer veicular uma informação proveniente de seu próprio intelecto, ou seja, informações às quais ele chegou por inferências, a partir de premissas que consistem, na grande maioria dos casos, em conhecimentos existentes, armazenados em seu intelecto durante sua vivência em sociedade.

A primeira característica que se nota em relação a esse uso diz respeito ao tipo de frase em que ocorre. Na língua francesa, Dendale (2010) reconhece o condicional de conjectura apenas em frases interrogativas. No PB, por outro lado, esse tipo de condicional apareceu, em sua maioria, em frases declarativas, e, ao contrário do que observou Dendale (2010), muito pouco em frases interrogativas, totalizando apenas quatro ocorrências. Por essa razão, neste artigo será apresentado um exemplo desse uso em uma frase declarativa.

(08) Se aconteceu assim com um projeto menos ambicioso, imagine a confusão que dará a tentativa de colocar todos os países da região em uma ação conjunta, que, fatalmente, teria a liderança dos EUA, dada a formidável disparidade de meios entre Washington e qualquer um dos países latinoamericanos/caribenhos. (Folha de S. Paulo, 03/01/12) 
É possível verificar que, na ocorrência (08) apresentada acima, o locutor faz uma asserção hipotética a respeito do evento informado e essa asserção é obtida a partir de uma inferência baseada em uma premissa maior, que permite ao locutor chegar à informação. O jornalista possui um conhecimento de saber comum, que se mostra como a premissa a partir da qual ele infere a informação veiculada.

$>$ Premissa: Sabe-se que existe uma enorme disparidade de meios entre Washington e qualquer um dos países latino-americanos/caribenhos, ou seja, sabe-se que os EUA têm muito mais poder do que qualquer um desses países.

$>$ Inferência feita a partir da premissa: caso todos os países da região se juntassem em uma ação conjunta, essa teria a liderança dos EUA, o país mais poderoso entre todos.

O condicional, portanto, veicula uma informação obtida por inferência, feita pelo próprio locutor que, por sua vez, se baseou em seus conhecimentos de mundo (premissas), certamente questionáveis, na medida em que foram obtidos de maneira indireta, por meio de noticiários, por exemplo. A informação, portanto, mostra-se como hipotética e não confirmada - o locutor veicula a informação com pouca segurança, dado que as premissas não foram verificadas diretamente.

PB:

Concluindo, o condicional de conjectura apresenta as seguintes características no

a) pode ocorrer em frases interrogativas ou declarativas;

b) nas frases em que ocorre indica que a informação provém do próprio locutor;

c) indica que o locutor obteve a informação a partir de inferência que se baseia em premissas que podem consistir, por exemplo, em conhecimentos gerais de saber comum, armazenados em seu intelecto;

d) a informação à qual se chega por inferência configura-se como uma asserção hipotética e conjectural, uma vez que as premissas se configuram em evidências obtidas, na grande maioria dos casos, de maneira indireta (a partir de fontes externas), não podendo o locutor atestá-las diretamente;

e) o grau de certeza do locutor a respeito da informação é menor;

f) há um comprometimento do locutor em relação à informação veiculada, uma vez que esta provém de um raciocínio feito por ele mesmo. No entanto, esse comprometimento é relativizado justamente pelo fato de que a asserção é feita com cautela, por meio do condicional, que marca um menor grau de compromisso com a factualidade da informação, mostrando-se como uma forma neutra, distante e imparcial.

\section{Considerações finais}

Neste trabalho, propôs-se fazer a descrição e análise de um tipo de marcador de evidencialidade que vem sendo estudado nas línguas românicas em geral (português europeu, francês, espanhol e italiano) por vários autores, o condicional de valor evidencial. Não há, no PB, análises que tratem especificamente desse uso. 
Inicialmente, lançou-se a hipótese de que, apesar de a expressão da evidencialidade no PB ser feita primordialmente por meios lexicais, o morfema do condicional (ou futuro do pretérito) poderia ser considerado como uma forma especializada de se marcar gramaticalmente a evidencialidade reportativa ou a evidencialidade inferencial, no PB.

As ocorrências com o condicional, inicialmente, foram postas em contraste em testes de substituição, nos quais o condicional foi substituído por outros tempos verbais do modo indicativo, para que fosse possível verificar se o morfema do condicional é o único que pode veicular sentidos evidenciais. Com esses testes, foi possível concluir que, assim como já se observou em outras línguas, o condicional, de fato, pode ser considerado uma forma especializada de se marcar gramaticalmente a evidencialidade indireta (reportativa e inferencial) no PB.

Feitos os testes, passou-se à descrição das características dos dois tipos de condicional de valor evidencial em estudo. Em resumo, o que se observou foi que o condicional de retomada da informação atua, juntamente com os outros marcadores de evidencialidade reportativa, indicando que a informação foi obtida indiretamente, por meio de uma fonte externa. O locutor utiliza esse tipo de condicional para reforçar o fato de que não validou diretamente a informação que veicula, caracterizando-a como não confirmada e incerta, em relação à qual, portanto, ele não pode se comprometer. $\mathrm{O}$ condicional indica, dessa forma, que a validade da informação está fora da alçada do locutor, não podendo ele ser responsabilizado pelos fatos veiculados. A forma do condicional permite então o estabelecimento de um distanciamento entre o locutor e seu texto, ou ainda, um não comprometimento dele com os fatos veiculados.

Com o condicional de conjectura, por outro lado, o locutor indica que as informações são resultados de inferências feitas por ele mesmo. Essas inferências, por sua vez, se baseiam em premissas que são, na maioria dos casos, conhecimentos existentes que foram armazenados em seu intelecto e adquiridos certamente de maneira indireta, por meios de comunicação diversos, por exemplo. Assim, os conhecimentos, ou premissas a partir das quais o locutor faz as inferências, chegando às informações veiculadas, são evidências indiretas, ou seja, que não foram validadas diretamente pelo locutor. Em razão disso, prefere-se transmitir essas informações inferidas como sendo asserções hipotéticas e não confirmadas. Nesse sentido, com o condicional de conjectura, o locutor consegue relativizar seu comprometimento com as informações inferidas por ele, na medida em que transmite as informações como tendo caráter hipotético. Assim, o condicional de conjectura, ainda que em menor grau, também permite um distanciamento entre o locutor e os conteúdos veiculados em seu texto.

Concluiu-se então que, no domínio jornalístico, existem motivos discursivos, tais como a exigência de objetividade nos textos, que condicionam o aparecimento desse marcador gramatical de evidencialidade indireta, de modo que se poderia até falar em certa obrigatoriedade, nesses gêneros, de haver a marcação de fatos relatados e inferidos por meio do condicional, uma forma distante, neutra e imparcial, ou seja, perfeitamente adequada aos propósitos do jornalismo, uma vez que possibilita o estabelecimento de um distanciamento entre o jornalista e seu texto.

A visão de língua adotada pelo funcionalismo foi determinante para a descrição. Considerando a língua em sua função comunicativa, como instrumento de interação, foi observado que as escolhas formais dos falantes não são aleatórias, mas que, no momento 
de construir seus enunciados, faz-se uma antecipação das possíveis reações dos interlocutores, de modo que, a partir dessas antecipações, para evitar ou não possíveis interpretações desses interlocutores, escolhem-se as formas linguísticas consideradas mais adequadas para determinados fins.

Concluindo, espera-se que o presente trabalho tenha introduzido e contribuído para a compreensão do condicional como um novo marcador de evidencialidade indireta, que se mostra recente nos estudos da área, principalmente nos estudos sobre evidencialidade no PB.

\section{REFERÊNCIAS}

AIKHENVALD, A. I. Y. Evidentiality. Oxford: Oxford University Press, 2004.

DALL'AGLIO HATTNHER, M. M. et al. Uma investigação funcionalista da modalidade epistêmica. In: NEVES, M. H. M. (Org.). Descrição do Português: definindo rumos de pesquisa. Araraquara: Cultura Acadêmica, 2001. p. 103-143.

. Pesquisas em sintaxe: a abordagem funcionalista da evidencialidade. In: MASSINI CAGLIARI, G. et al. (Org.). Trilhas de Mattoso Câmara e outras trilhas: fonologia, morfologia e sintaxe. Araraquara: Cultura Acadêmica, 2007. p. 103-145.

DENDALE, P. Le marquage épistémique de l'énoncé: esquisse d'une théorie avec applications au français. 1991. 383 f. Tese (Doutorado) - Université d'Anvers, Antwerpen, Bélgica.

. Il serait à Paris en ce moment. Serait-il à Paris? A propos de deux emplois épistémiques du conditionnel. Grammaire, syntaxe, sémantique. In: CASTRO, C. A., BANGO DE LA CAMPA, Fl.; DONAIRE, M. L. Liens linguistiques. Études sur la combinatoire et la hiérarchie des composants. Bern: Peter Lang, 2010. p. 291-317.

DENDALE, P.; TASMOWSKI, L. Présentation. L'évidentialité ou le marquage des sources du savoir. Langue française, Paris, v. 102, p. 3-7, 1994.

. Introduction: Evidentiality and related notions. Journal of Pragmatics, Amsterdam, v. 33, n. 3, p. 339-348, 2001.

DIK, S. Studies in functional grammar. London: Academic Press, 1980.

HENGEVELD, K.; MACKENZIE, L. Functional Discourse Grammar. A typologicallybased theory of language structure. Oxford: Oxford University Press, 2008.

MARCUSCHI, L. A. Produção textual, análise de gêneros e compreensão. São Paulo: Parábola, 2008.

NEVES, M. H. M. Gramática de usos do português. São Paulo: Editora UNESP, 2000.

Texto: Gramática. São Paulo: Contexto, 2006.

NUYTS, J. Epistemic modal adverbs and adjectives and the layered representation of conceptual and linguistic structure. Linguistics, Hawthorne, v. 31, p. 933-969, 1993.

Epistemic modal qualifications: on their linguistic and conceptual structure.

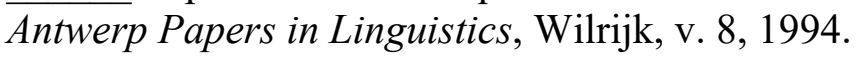


. Subjectivity as an evidential dimension in epistemic modal expressions. Journal of Pragmatics, Amsterdam, v. 33, n. 3, p. 383-400, 2001.

OLIVEIRA, T. Valores de (inter)subjetividade na análise semântica: a marcação da distância. 2013. 195 f. Tese (Doutorado em Linguística Portuguesa) - Universidade Nova de Lisboa, Lisboa, 2013.

SQUARTINI, M. The internal structure of evidentiality in Romance. Studies in Language, v. 25(2), p. 297-334, 2001.

Recebido em: 31/08/2016

Aprovado em: 29/11/2016 